\title{
Pablo Estefanoni. Los inconformistas del centenario: Intelectuales, socialismo y nación en una Bolivia en crisis (1925-1939). 384 páginas. La Paz: Plural
} Editores, 2015.

En Los inconformistas del Centenario: Intelectuales, socialismo y nación en una Bolivia en crisis (1925-1939), el historiador y periodista argentino Pablo Stefanoni utiliza la efervescencia cultural y las contradicciones fermentadas por los festejos del centenario de la independencia para trazar un mapa de las recepciones, apropiaciones y difusiones de nuevas ideas antiliberales que luego pondrían en jaque a las bases de legitimidad de la república liberal-oligárquica boliviana de entonces. Frecuentemente tratado apenas como un período de transición entre el colapso de dicha república y la Revolución Nacional del 52 (y en ese sentido la mayoría de las veces empezando apenas tras la debacle militar del Chaco), Stefanoni propone entenderlo como un período con características propias e importantes que ameritan ser estudiadas por su propia relevancia histórica. Fruto de su tesis doctoral en la Universidad de Buenos Aires (UBA), el libro se compone de una introducción y una conclusión generales, y tres partes (cada una con una breve introducción y conclusión) de tres, cuatro y dos capítulos respectivamente.

En la Primera Parte, titulada "Una nación más ancha. La Bolivia del Centenario y la irrupción de la cuestión nacional", Stefanoni nos relata las frustraciones del país tras los veinte años de hegemonía del Partido Liberal y su proyecto modernizador, y las novedades y contradicciones políticas traídas por el gobierno Republicano de Bautista Saavedra. El autor nos 
muestra como Saavedra buscó utilizar los festejos del centenario de la independencia en 1925 como demostración de una nación que se encaminaba por los senderos de la modernización y el desarrollo, pero desde a las contradicciones de una presidencia que sí trajo novedosas (aunque limitadas) innovaciones en política social, pero mantuvo el régimen oligárquico en sus bases y terminó fomentando un semillero de descontentos. Descontentos que luego inaugurarían un fecundo periodo de re-imaginación nacional a partir de nuevas ideas como el marxismo o el vitalismo que llegaban al país desde Chile, Argentina o Europa.

También a contracorriente de muchos estudios sobre ese periodo de renovación de ideas en el país, que se dedican a evaluar supuestas deformaciones entre la doctrina original y su recepción boliviana, Stefanoni busca entender los caminos y razones que llevaron a asimilaciones de una misma ideología-matriz en claves nacionales distintas y a veces contradictorias y se dedica a demostrar las redes y medios de difusión de las nuevas ideas, tal como la revista Arte y Trabajo, editada en Cochabamba en los años 1920 por el anarquista Cesáreo Capriles. Personaje curioso, cuya sui generis biográfica rescata Stefanoni, dando a conocer que antes de editar Arte y Trabajo, intentó (por iniciativa propia y llevando materiales a lomo de mula) instalar teléfonos en Uncía y trabajó en Aduanas en la Amazonía boliviana. En 1950, envió una enigmática carta a su amigo José Antonio Arze, que en 1949 había fundado el PIR (Partido de la Izquierda Revolucionaria), pidiendo no contestarla debido a que viajaría con rumbo desconocido y desapareció sin dejar rastros (Stefanoni 65 y ss).

Arte y Trabajo sirvió de tribuna y espacio de difusión a nuevas y heterodoxas ideas de las más distintas matrices y de primer espacio de actuación intelectual de jóvenes que luego cobrarían gran relevancia en la vida política nacional, como Carlos Montenegro, Augusto Céspedes o José Antonio Arze. La búsqueda de dichas redes y caminos de difusión permite al autor analizar los primeros intentos de acercamiento entre los nacientes movimiento obrero y partidos de izquierda y las comunidades indígenas lo que llevaría a las acusaciones gubernamentales de comunismo hacia los indígenas sublevados de Chayanta- o las influencias de las revoluciones mexicana y rusa en la radicalización de los estudiantes a fines de la década, en el primer congreso estudiantil boliviano de 1928. 
En la Segunda Parte, "Una nación esquiva. Comunismo, indianismo, feminismo: nuevas sensibilidades en tiempos de guerra", el autor nos lleva por los caminos y personajes que actuaron en la recepción, asimilación e hibridaciones, en clave boliviana, del marxismo, indianismo y feminismo. Stefanoni nos muestra los desencuentros entre los marxistas locales y la Comintern soviética, que llevaría al tardío reconocimiento de un PC oficial boliviano recién en 1950, pese al entusiasmado y sincero estalinismo del mencionado Antonio Arze; los impactos de las ideas vitalistas tras la visita del conde de Keyserling a La Paz en 1929 y las hibridaciones que produjo con el naciente indigenismo local; y las divisiones que la Guerra del Chaco generó al interior de los primeros grupos feministas, entre los radicales, que abogaban por el pacifismo y los que se dirigieron a organizar brigadas de enfermeras para auxiliar el esfuerzo bélico nacional. Del mismo modo, nos da cuenta de divergencias, a veces programáticas, a veces personales, que impidieron una unificación de las izquierdas en general y de los grupos marxistas en particular, además de los clivajes, también traídos por el Chaco, entre los grupos marxistas que abogaron por la "guerra a la guerra" y fueron posteriormente atacados por su supuesta falta de patriotismo, por la izquierda nacionalista, y vistos con desconfianza por los militares, actores-clave en la coyuntura venidera. Es interesante notar la complejidad de la construcción de horizontes de emancipación social hasta entonces inexistentes en un contexto altamente heterogéneo y desigual como el boliviano. En un periodo en que, tal como establece la célebre frase de Gramsci, el viejo se moría sin que el nuevo acabase de nacer, se buscaba, por ejemplo, fórmulas de inclusión de las mujeres que (sin todavía llegar a cuestionar las bases excluyentes de la ciudadanía censitaria) chocaban con cuestiones prácticas de cómo hacerlo sin necesariamente incluir a los "salvajes indígenas" o algún otro grupo considerado indeseable en una todavía inimaginable ciudadanía universal.

Mientras en las dos primeras partes Stefanoni se concentra en el surgimiento de nuevas ideas y sus recepciones y adaptaciones intelectuales locales, en la Tercera Parte (“¿¿Una nación más densa? El socialismo como salvación nacional") se enfoca en el experimento práctico que por primera vez buscó aplicarlas: el Socialismo Militar de Toro y Busch. En un contexto en que muchos concordaban con la falencia del régimen vigente, pero en el que también mucho se divergía con relación a soluciones, el Socialismo Militar cobijó a grupos y militantes muy heterogéneos, bajo el nombre de un 'socialismo' genérico y de contenido 
difuso, capaz de contener todas las aspiraciones y contradicciones del efervescente periodo. Y así, trasladó la intensa disputa de ideas al interior del mismo gobierno y sus políticas, provocando los conocidos vaivenes de esa crucial coyuntura de la historia nacional. Stefanoni nos muestra como el liberalismo, en cuanto ideología política general, pasa a ser asociado con las causas del atraso boliviano, y como empezó a fermentar un caldo donde novedades intelectuales de cualquier matriz eran buscadas como alternativas, con tal de que sonaran antiliberales. Esto sirve para matizar ideas a veces difundidas de que el Socialismo Militar boliviano fue construido con base en un modelo filo-fascista. Si bien es cierto que ideas nazi-fascistas tuvieron acogida (aunque limitada) en el período estudiado por el libro, aquello se dio mucho más por su carácter no-liberal, por la adecuación de sus rasgos corporativistas de organización con tradiciones ya presentes en la política local, y por los ecos que la interpretación una nación alemana humillada por la guerra, pero que se reconstruía al recuperar sus energías vitales, traían por comparación con la situación boliviana de entonces, que por reales identificaciones doctrinarias. El antisemitismo inicial que evidentemente existió en el grupo que se convertiría en el MNR y en el presidente de origen alemán, Germán Busch, queda superado cuando éste ordenó, por ejemplo, una política de concesión de visas a judíos en fuga. Aunque el intento se haya frustrado por la corrupción de las autoridades consulares responsables de su aplicación, el hecho sirve para desmitificar el supuesto filo-nazismo de Busch. En muchísimos sentidos políticos e institucionales, como nos muestra el autor, el socialismo militar buscó emular al régimen postrevolucionario mexicano mucho más que al eje nazi-fascista, y recibió de aquél apoyo concreto.

Además de la cuidadosa reconstrucción de la trayectoria de importantes ideas y personajes de los principios del siglo XX boliviano, el mérito del trabajo de Stefanoni radica en resaltar la importancia del período como un verdadero "momento constitutivo" (en términos del sociólogo René Zavaleta) en el que se generaron o reforzaron importantes trazos de la cultura política boliviana, tal como la idea de "cogobierno obrero". Inaugurada por indicación del marxista Waldo Álvarez al Ministerio de Trabajo de Toro, el principio se convertiría en casi dogma para I a izquierda laborista tras la Revolución del 52 y aún sigue vigente como interpelación política en la contemporaneidad, como lo demuestra 
la idea de "gobierno de los movimientos sociales" de la presidencia de Evo Morales (2006-actual). Al mismo tiempo, el libro aporta importantes detalles anteriormente perdidos en el tiempo de los mega-relatos épicos, tan comunes en la bibliografía bolivianista, y que ayudan a matizar hechos tenidos como verdad histórica, como por ejemplo el alineamiento del Partido de la Izquierda Revolucionaria (PIR) del mencionado Arze o el totalitarismo de Busch, y así nos brinda bases sólidas con las cuales reevaluar el presente boliviano y sus vicisitudes.

Clayton Mendonça Cunha Filho Universidade Federal do Ceará

\section{$(c))$ Br}

ULS D-Serle $\begin{aligned} & \text { This journal is published by the University Library System of the } \\ & \text { University of Pittsburgh as part of its D-Scribe Digital Publishing }\end{aligned}$ Program, and is cosponsored by the University of Pittsburgh Press. 